\title{
Los derrubios estratificados holocenos de Praón (Picos de Europa, Montañas Cantábricas)
}

\section{Holocene stratified scree of Praón (Picos de Europa, Cantabrian Mountains)}

\author{
RUIZ-FERNÁNDEZ, J. ${ }^{1 *}$, GARCÍA-HERNÁNDEZ, C. ${ }^{1}$, FERNÁNDEZ, S. ${ }^{2}$ \\ ${ }^{1}$ Departamento de Geografía, Universidad de Oviedo, Oviedo, España. \\ ${ }^{2}$ Departamento de Geología. Universidad de Oviedo. Oviedo, España. \\ * Contacto: Jesús Ruiz-Fernández: ruizjesus@uniovi.es
}

\section{Resumen}

En este artículo se estudian los derrubios estratificados y cementados presentes en Praón, un sector de la baja montaña de los Picos de Europa. La realización de trabajo de campo sistemático ha permitido establecer el contexto geomorfológico en el que están insertos los derrubios estudiados, caracterizándolos desde el punto de vista sedimentológico. Se han obtenido dos edades ${ }^{14} \mathrm{C}$ en restos de gasterópodos insertos a 4 metros $(10.775 \pm 325$ años cal BP) y a 1,7 metros (5.175 \pm 135 años cal BP) de profundidad, infiriendo las condiciones de precipitación del cemento carbonatado a partir de la realización de análisis isotópicos. Estas condiciones habrían sido más frías para la muestra más antigua y mucho más cálidas para la más reciente. Los resultados de este trabajo evidencian que, derrubios estratificados como los estudiados, los cuales son abundantes en el área de los Picos de Europa, podrían haberse 
originado en condiciones climáticas diversas y no necesariamente de frío extremo, ni exclusivas de ambientes periglaciares sensu stricto, no teniendo tampoco por qué corresponderse, desde el punto cronológico, con el Tardiglaciar (en cronologías de 14 a $10 \mathrm{ka}$ ), el periodo frío al que tradicionalmente han sido adscritos de forma relativa en las Montañas Cantábricas.

Palabras clave: Derrubios estratificados cementados, gonfolitas, Holoceno, Picos de Europa, Montañas Cantábricas.

\begin{abstract}
In this paper we study the stratified and cemented scree located in Praón, a low mountain sector of the Picos de Europa (Cantabrian Mountains). The field work has allowed to establish the geomorphological context in which the studied stratified scree are inserted, characterizing them from the sedimentological point of view. ${ }^{14} \mathrm{C}$ ages have been obtained in remains of gastropods found at 4 meters deep (10.775 \pm 325 years cal BP) and 1.7 meters deep (5.175 \pm 135 years cal BP). Moreover, the precipitation climate conditions of carbonated cement have been obtained measuring the isotope ratio of both samples. These conditions would be colder for the oldest sample and warmer for the recent one. The results of this study show that stratified scree such as those studied, which are abundant in the area of the Picos de Europa, could have been originated in relation to diverse climatic conditions, and that they do not necessarily have to correspond, from the chronological point of view, with the cold stage of Lateglacial (14 to $10 \mathrm{ka}$ ) to which traditionally they have been assigned through relative chronology, in the Cantabrian Mountains.
\end{abstract}

Key words: Stratified cemented scree, gonfolites, Holocene, Picos de Europa, Cantabrian Mountains. 


\section{INTRODUCCIÓN}

En las últimas décadas los estudios sobre periglaciarismo han experimentado un importante impulso en el ámbito de las Montañas Cantábricas. Este tipo de estudios se centraron primero en el reconocimiento de las formas y depósitos heredados de condiciones climáticas pasadas, presentes en el citado ámbito tanto en sectores de baja como de media y alta montaña (ej. ALONSO, 1989; GARCÍA DE CELIS, 1991, 1997, 2002; CASTAÑÓN Y FROCHOSO, 1994; RODRÍGUEZ-PÉREZ, 1995, 1998, 2015; JIMÉNEZ-SÁNCHEZ， 1996; GONZÁLEZ-GUTIÉRREZ, 2002; REDONDOVEGA et al., 2004; GÓMEZ-VILLAR et al., 2011; SANTOS-GONZÁLEZ, 2010; PELLITERO et al., 2011; RUIZ-FERNÁNDEZ, 2015; RUIZ-FERNÁNDEZ et al., 2016); si bien, posteriormente, dichos estudios se han focalizado en el conocimiento de la morfodinámica periglaciar actual en las áreas más elevadas de las Montañas Cantábricas, situadas en enclaves como los Picos de Europa, Fuentes Carrionas o el Macizo de las Ubiñas (ej. CASTAÑÓN Y FROCHOSO, 1998; SERRANO Y GONZÁLEZ-TRUEBA, 2004, GONZÁLEZTRUEBA, 2007; GONZÁLEZ-TRUEBA Y SERRANO, 2010; PELLITERO, 2012; GALLINAR et al., 2014; RUIZ-FERNÁNDEZ et al., 2014; RUIZ-FERNÁNDEZ, 2015; RUIZ-FERNÁNDEZ et al., 2016). Muchas de las investigaciones recientemente desarrolladas en este ámbito geográfico, tratando de explicar la morfodinámica periglaciar activa en las áreas de alta montaña, se han concentrado en el seguimiento y análisis del régimen térmico del suelo, el aire y las paredes rocosas (ej. CASTAÑÓN Y FROCHOSO, 1998; GONZÁLEZ-TRUEBA Y
SERRANO, 2010; SANTOS-GONZÁLEZ et al., 2009; PELLITERO 2012; PISABARRO et al., 2017, RUIZ-FERNÁNDEZ et al., 2014, 2017), mientras otras cuestiones relativas al periglaciarismo continúan sin ser estudiadas en profundidad en las Montañas Cantábricas. Del mismo modo, gran parte de la superficie de estas montañas con evidencias periglaciares no ha sido examinada en detalle.

En este sentido, uno de los mayores vacíos de conocimiento a los que se enfrenta el estudio del periglaciarismo cantábrico es la práctica ausencia de dataciones absolutas que permitan establecer una secuencia cronológica básica. Cabe citar, como excepción a lo señalado, las gravas estratificadas y cementadas que han sido datadas en el Alto Duje en 79.1 +7.3/-6.6 Ka y 55.4 +3.0/$3.0 \mathrm{Ka}$ por CASTAÑÓN Y FROCHOSO (1996), así como las dataciones de $C^{14}$ efectuadas en el rellano de obturación glaciar de la majada de Belbín (Macizo Occidental de los Picos de Europa) por Ruiz-Fernández et al. (2016). En este sector, la unidad inferior de un sondeo de $540 \mathrm{~cm}$ de largo, constituida por un depósito periglaciar de arenas y gravas angulosas y subangulosas de caliza, y en menor medida de pizarra, fue datada en $37.2 \mathrm{ka}$ cal BP a $540 \mathrm{~cm}$ de profundidad y en $29.4 \mathrm{ka}$ cal BP a $386 \mathrm{~cm}$; atestiguando, por tanto, la formación de depósitos periglaciares coetáneos a la fase de máxima extensión de los hielos dentro de la Última Glaciación en las Montañas Cantábricas (RUIZ-FERNÁNDEZ et al., 2016).

La falta de dataciones absolutas en relación con los depósitos periglaciares es un problema extensible a toda la Península Ibérica (OLIVA et al., 2016). No ocurre lo mismo con las formas y depósitos de origen glaciar, que han sido profusamente datadas 
en los principales conjuntos montañosos de la Península Ibérica (ej. VIDAL ROMANÍ Y FERNÁNDEZ MOSQUERA, 1999; VIDAL ROMANÍ et al., 1999; JIMÉNEZ Y FARIAS, 2002; GARCÍA-RUIZ et al., 2003, 2010, 2014; DELMAS et al., 2008; SANJURJO et al., 2009; PALACIOS et al., 2011, 2012, 2015; RODRÍGUEZ-RODRÍGUEZ et al., 2011, 2014a y 2014b; GÓMEZ-ORTIZ et al., 2012; CARRASCO et al., 2013; DOMÍNGUEZ-VILLAR et al., 2013; FROCHOSO et al., 2013; JIMÉNEZ et al., 2013; PELLITERO, 2013; SERRANO et al., 2013; RUIZ-FERNÁNDEZ et al., 2016).

La ausencia de un marco cronológico preciso provoca que, en numerosas ocasiones, se den por válidas cronologías relativas sobre diversos depósitos periglaciares (o identificados como tales), lo que podría generar numerosos errores al adscribir cronológicamente dichos depósitos, al correlacionarlos con otras formas y depósitos, así como a la hora de establecer una secuencia evolutiva coherente. En el marco de las Montañas Cantábricas, una de las adscripciones cronológicas relativas más comunes consiste en atribuir los depósitos estratificados o del tipo grèzes litées (Ozouf et al., 1995) al Tardiglaciar, un periodo frío acontecido entre 14 y $10 \mathrm{ka}$ (EHLERS et al., 2006; SERRANO et al., 2012; 2013) al que también han sido asignados de forma relativa algunos de los glaciares rocosos relictos del Macizo Asturiano a partir de relaciones morfoestratigráficas con otros depósitos y formas de modelado, principalmente glaciares (ALONSO, 1989). Los datos que se desprenden de los análisis sedimentológicos de diversos sondeos obtenidos en otros tantos sectores de las Montañas Cantábricas como el lago Enol (MORENO et al., 2011), o Campo Mayor en los Puertos de Áliva (SERRANO et al., 2012), permiten reconocer, efectivamente, un episodio frío y seco entre 13,5 y 11,6 ka (Younger Dryas) en estas montañas.

Los derrubios estratificados han sido objeto de diversos estudios a nivel de la Península Ibérica. Además de su inclusión en trabajos geomorfológicos de temática más amplia (ej. Rodríguez Pérez, 1995, 1998), hay diversas publicaciones específicas focalizadas en su estudio sedimentológico y sus implicaciones paleoambientales (ej. MARCO MOLINA, 2000; GARCÍA-RUIZ et al., 2001; MARCO MOLINA et al., 2018). Precisamente, en el presente trabajo se han caracterizado sedimentológicamente, datado mediante ${ }^{14} \mathrm{C}$ y estudiado desde el punto de vista isotópico los derrubios estratificados existentes a los pies de la vertiente meridional de la Sierra de Dobros (Picos de Europa), con los objetivos de: i) comprobar si las edades obtenidas pertenecen o no a los periodos fríos a los que normalmente son atribuidos este tipo de depósitos, ii) establecer las relaciones isotópicas de $\delta^{18} \mathrm{O}_{\mathrm{PDB}} \% \mathrm{y}$ $\delta^{13} \mathrm{C}_{\mathrm{PDB}}$ de las muestras datadas $\mathrm{y}$, iii) discutir cuales podrían ser los factores determinantes en la formación de los derrubios estratificados estudiados, en el caso de que tanto las edades obtenidas como resultados de los análisis isotópicos no permitan inferir condiciones climáticas frías durante su formación.

\section{II. ÁREA DE ESTUDIO}

El área de estudio del presente trabajo se centra en la Sierra de Dobros, que con sus $\sim 3,8 \mathrm{~km}$ de longitud, siguiendo una orientación WNW-ESE, constituye el apéndice nororiental de la Sierra de Cabezu Llerosos. 
Esta última alineación, a su vez, conforma una prolongación hacia el Noreste del Macizo Occidental de los Picos de Europa (Figura 1). Las altitudes de la Sierra de Dobros oscilan entre los 1063 m s.n.m. que alcanza el Cuetu Cananda, y los 130 m s.n.m. del río Cares en Arenas de Cabrales. La Sierra de Dobros, está constituida parcialmente por una escama cabalgante de rumbo E-W y vergencia hacia el Sur. Así, la vertiente septentrional de la alineación está integrada, principalmente, por materiales estefanienses pertenecientes a la Cuenca de GamonedoCabrales-Panes (WAGNER, 1967; MARCOS, 1967; MARTÍNEZ-GARCÍA, 1981; SÁNCHEZ Y TRUYOLS, 1983; Navarro, Leyva y Villa, 1986; MERINO-TOMÉ, 2004), concretamente por lutitas y areniscas alternantes, calizas y conglomerados, discordantes con respecto al resto de materiales paleozoicos presentes. Este roquedo, esencialmente detrítico, da lugar a una serie de interfluvios de moderada pendiente que descienden progresivamente hacia el valle del río Casaño y la depresión de Arenas de Cabrales. En cambio, el eje de la Sierra de Dobros está constituido por calizas del Carbonífero superior intensamente karstificadas, las cuales dan paso hacia el Sur a una vertiente muy escarpada, labrada igualmente en calizas, a cuyos pies se han depositado los derrubios estratificados estudiados en este trabajo. La alineación de Dobros queda separada del sector del Cuetón-Vallisondi (labrado en cuarcitas ordovícicas) por el arroyo de Praón, afluente del río Cares por su margen izquierda (Figura 1), que se ha encajado entre las citadas cuarcitas y las calizas a favor del afloramiento de dos estrechas fajas de rumbo E-W de areniscas y mi- croconglomerados del Devónico y de calizas nodulosas rojas de edad Viseense inferiorNamuriense inferior, conocidas como "Formación Alba", "Genicera" o "caliza Griotte” (MARTÍNEZ-GARCÍA, 1981; SÁNCHEZ Y TRUYOLS, 1983; JULIVERT Y NAVARRO, 1984; MARTÍNEZ-GARCÍA Y RODRÍGUEZ-FERNÁNDEZ, 1984).

Desde el punto de vista climático, se trata de un ámbito de tipo oceánico, caracterizado por temperaturas medias anuales suaves (de 10,8 a $13,8^{\circ} \mathrm{C}$ en función de la altitud), una amplitud térmica moderada y precipitaciones abundantes, del orden de $\sim 1400 \mathrm{~mm} /$ año (Ruiz-Fernández et al., 2008). La vegetación de la sierra está dominada por el encinar cantábrico en los afloramientos de topografía más fragosa (labrados en calizas), por pastizales y aulagares sobre los sectores calcáreos de mayor altitud, así como por formaciones de landa atlántica acidófila, bosques mixtos, robledales y sotos de castaños sobre los materiales silíceos (RUIZFERNÁNDEZ, 2006a, 2006b; RUIZ-FERNÁNDEZ et al., 2008).

En esta sierra existió cierta actividad minera durante los S. XIX y XX focalizada en la explotación de mineralizaciones de hierro, manganeso y cobre, asociadas a las calizas carboníferas (GUTIÉRREZ-CLAVEROL Y LUQUE-CABAL, 2000). El pasado minero de este ámbito y las actividades agrosilvo-pastoriles son las principales acciones antrópicas desarrolladas en este espacio (RUIZ-FERNÁNDEZ, 2006a), que carece de núcleos de población permanentes salvo en su extremo Norte, entorno al valle del río Casaño hasta su unión con el Cares, donde se encuentran los núcleos de Inguanzo, Carreña, Poo y Arenas. 


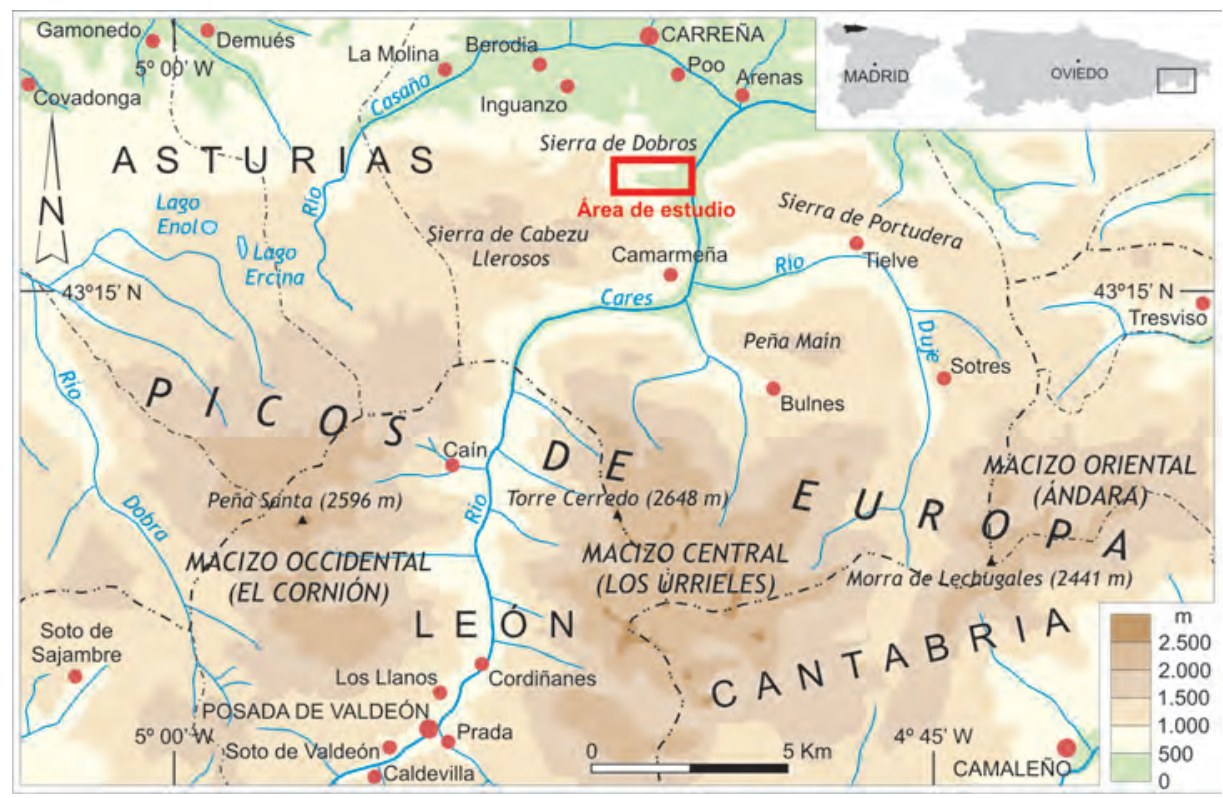

Fig. 1 Localización del área de estudio.

\section{METODOLOGÍA}

La metodología ha consistido en la realización de trabajo de campo, a fin de establecer el contexto geomorfológico en el que están insertos los derrubios estratificados estudiados. La información obtenida ha permitido realizar un mapa geomorfológico del área siguiendo el sistema cartográfico RCP77 del Centre National de la Recherche Scientifique (CNRS) de Francia (JOLY, 1997), aunque con adaptaciones propias (RUIZ-FERNÁNDEZ, 2011: Figura 2). Paralelamente, se caracterizaron los derrubios estratificados desde el punto de vista sedimentológico (el alto grado de cementación que presentan los derrubios impidió la realización de análisis sedimentológicos más detallados), y se obtuvieron dos muestras con restos orgánicos -conchas de gasterópodos (caracoles) en ambos casos- para su datación mediante ${ }^{14} \mathrm{C}$. Las muestras fueron obtenidas a profundidades de $4 \mathrm{~m}$ (M1) y $1,7 \mathrm{~m}$ (M2), en el extremo oriental del sector ocupado por los derrubios (Figuras $3 \mathrm{y}$ 4). Las dataciones correspondientes fueron efectuadas en el laboratorio de radiocarbono de la Universidad Tecnológica de Silesia (Polonia). Las edades ${ }^{14} \mathrm{C}$ obtenidas fueron calibradas con el programa CALIB 7.0 y la curva IntCal13. Finalmente, se realizaron análisis isotópicos de las muestras M1 y M2 en el Servicio de Análisis de Isótopos Estables (NUCLEUS) de la Universidad de Salamanca. Para ello, se procedió a la obtención de $\mathrm{CO}_{2}$ para la determinación de relaciones isotópicas de $\delta^{18} \mathrm{O}_{\mathrm{PDB}} \% 0 \mathrm{y} \delta^{13} \mathrm{C}_{\mathrm{PDB}}$ $\%$ por reacción con $\mathrm{H}_{3} \mathrm{PO}_{4}$ al $103 \%$ a $25^{\circ} \mathrm{C}$. La determinación de las relaciones isotópicas se efectuó mediante espectrometría de masas de fuente gaseosa en modo "Dual Inlet”, empleando un espectrómetro SIRA- 
II. Estos resultados en los carbonatos de las muestras de derrubios M1 y M2, nos permitirán trazar y correlacionar las relaciones isotópicas de estos mismos isótopos regis- tradas en espeleotemas de cuevas del Norte de la Península Ibérica (el medio más similar al tratado en este estudio).

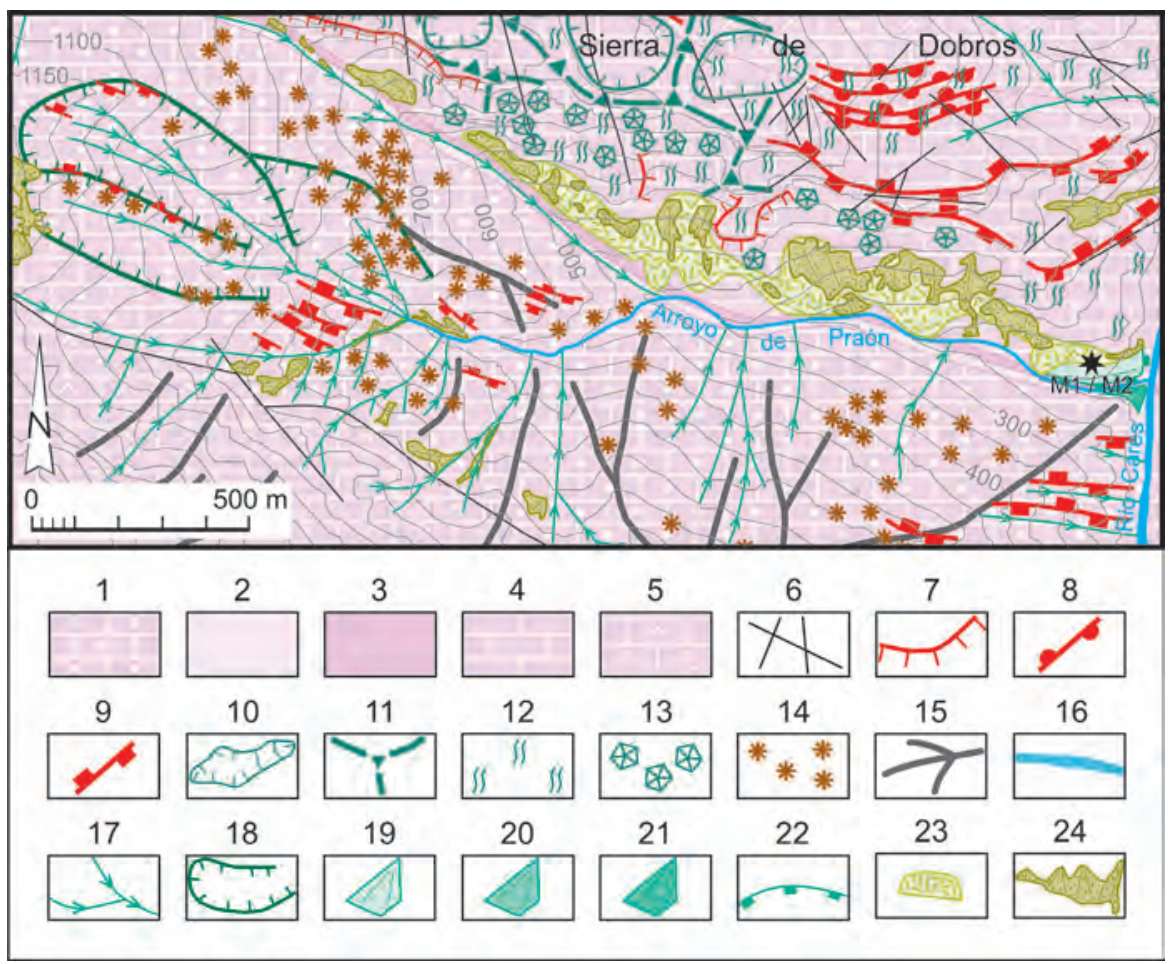

Fig. 2. Cartografía geomorfológica del área de Praón. 1.- Cuarcitas de la Formación Barrios (Ordovícico). 2.- Areniscas y microconglomerados de la Formación Ermita (Devónico). 3.- Caliza Griotte (Carbonífero). 4.- Calizas de Montaña (Carbonífero). 5.- Calizas de Picos de Europa (Carbonífero). 6.- Fallas y fracturas. 7.- Escarpe rocoso. 8.- Capa subvertical erosionada. 9.- Capa subvertical en resalte. 10.- Dolina. 11.- Relieve calcáreo residual. 12.- Campo de lapiaces. 13.- Porrones calcáreos. 14.- Tors cuarcíticos. 15.- Interfluvios. 16.- Río. 17.- Surcos de arroyada. 18.- Cabecera torrencial. 19.- Cono de deyección $(+22 \mathrm{~m})$. 20.- Cono de deyección $(+10 \mathrm{~m})$. 21.- Cono de deyección $(+5 \mathrm{~m})$. 22.- Borde abrupto de cono. 23.- Derrubios estratificados cementados. 24.- Taludes y conos de derrubios.

\section{RESULTADOS}

\section{Contexto geomorfológico de los derrubios estratificados}

Los derrubios estratificados estudiados en este trabajo se sitúan a los pies de la ver- tiente meridional de la Sierra de Dobros. Esta vertiente es muy escarpada en sus sectores medios y superiores, estando constituida en su totalidad por calizas del Carbonífero. En el sector distal, se han depositado los derrubios estratificados citados, que están fosilizados en numerosos sectores por can- 
chales actuales, definidos por el afloramiento de cantos y bloques de caliza, así como por la ausencia de matriz fina en superficie. A los pies de los derrubios estratificados se localiza el arroyo de Praón, el cual se ha encajado a favor del afloramiento de una serie de materiales menos resistentes, citados anteriormente -microconglomerados y areniscas devónicas y "caliza Griotte" (Carbonífero inferior)- que, en conjunto, tienen una potencia de unos $50 \mathrm{~m}$. Estos materiales están situados desde el punto de vista estratigráfico entre las calizas del Carbonífero superior, las cuales arman la culminación y la vertiente Sur de la Sierra de Dobros, y las cuarcitas ordovícicas que dan lugar a los interfluvios localizados inmediatamente al Sur de la anterior en el área de Vallisondi y la Cuesta Mediudía.

El arroyo de Praón, constituye un torrente de montaña en el que se diferencia netamente la correspondiente cabecera o área de captación de las escorrentías (un órgano colector a modo de cauce encajado que ha incidido el frente los derrubios estratificados estudiados), y un órgano difusor a modo de cono de deyección, colgado en la margen izquierda de dicho arroyo a $22 \mathrm{~m}$ sobre el nivel actual del río Cares, del cual es tributario este arroyo (Figura 2). El cono torrencial está compuesto por gravas, cantos y bloques subredondeados y subangulosos de cuarcita y caliza, que se hallan envueltos en una matriz fina de textura arenoso-limosa y están ligeramente cementados a techo en algunos sectores (Figura 3). Parte del cono torrencial se halla fosilizado, a su vez, por los derrubios estratificados estudiados (Figura 3). Además, en la margen derecha de la confluencia del arroyo de Praón con el río Cares, se conservan otros dos retazos de conos de deyección colgados a alturas de 10 y
$5 \mathrm{~m}$ con respecto al cauce actual (Figura 2). El desalojo de las formaciones superficiales que recubren los afloramientos cuarcíticos, así como el propio sustrato cuarcítico, intensamente arenizado en numerosos sectores, ha dejado en las vertientes numerosas capas cuarcíticas en resalte, así como tors de formas poliédricas (Figura 2).

\section{Características de los derrubios estratifica- dos, edades 14C obtenidas y resultados de los análisis isotópicos}

Los derrubios estratificados presentan un espesor máximo visible de $6 \mathrm{~m}$. Sin embargo, en la terminación oriental la potencia total del depósito estratificado es de $4 \mathrm{~m}$ (Figura 3). Los citados derrubios tienen gran continuidad lateral, puesto que se extienden a los pies de gran parte de la vertiente meridional de la Sierra de Dobros (Figuras 2), alcanzando una extensión de $\sim 14$ ha. Están compuestos por clastos homométricos, angulosos, estratificados e intensamente cementados. Generalmente, se da una alternancia de estratos integrados por gravas, junto con otros compuestos por pequeños cantos, siempre de caliza y con formas aristadas. Los clastos se hallan orientados de acuerdo con la inclinación de la pendiente $\left(\sim 20^{\circ}\right)$, encontrándose fuertemente cohesionados con posterioridad a su deposición, por un cemento carbonatado. En ocasiones aparecen intercalados algunos bloques, igualmente de caliza. En general, la matriz fina, de textura arcillosa, es escasa, salvo en algunos lechos intercalados y, especialmente, en la base, donde el depósito pasa de ser clasto-soportado a matriz-soportado, en diversos sectores. El frente de los derrubios cementados tiene un escarpe abrupto, pues se halla intensamente karstificado (Figuras 
3 y 4). Por tanto, hay numerosas hornacinas y oquedades de diverso tamaño a lo largo de todo el escarpe. A su vez, en el frente son frecuentes los espeleotemas. En la erosión del escarpe también juega un papel sustancial la incisión basal del arroyo de Praón, el cual discurre a los pies de los derrubios estratificados en su tramo final.

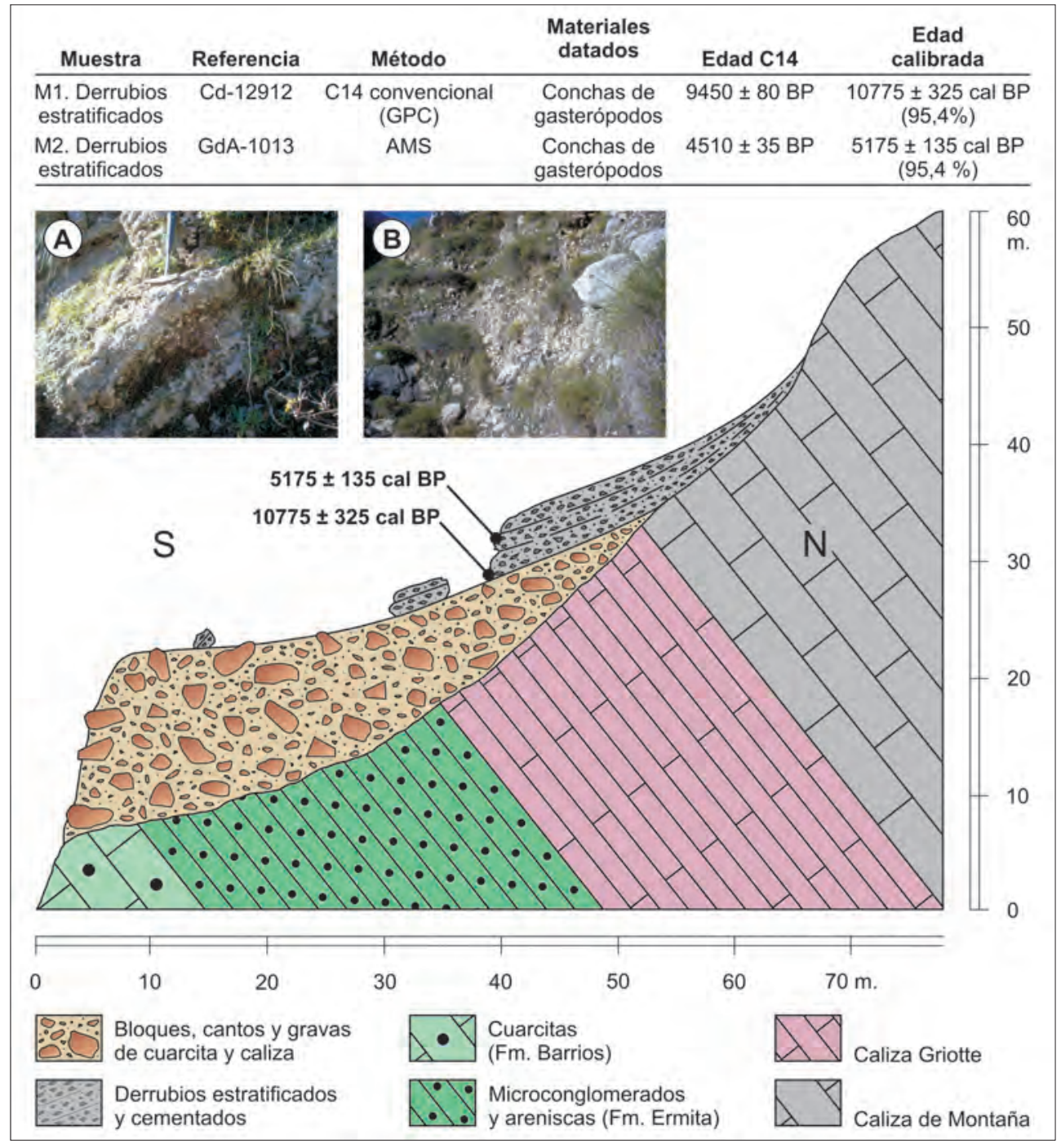

Fig. 3. Perfil geomorfológico de los derrubios estratificados y del cono torrencial de Praón (parte inferior de la figura), y descripción y resultados de las dataciones de $14 \mathrm{C}$ efectuadas (parte superior). Detalle de las gravas periglaciares intensamente cementadas que fosilizan al cono de deyección (A), y de la gran heterometría que presentan los materiales del cono torrencial (B). Modificado de RUIZ-FERNÁNDEZ (2006a). 
Las muestras datadas, compuestas en ambos casos por restos de moluscos gasterópodos, se recogieron en la terminación oriental del área ocupada por los derrubios estratificados (Figuras 2 y 3). En este sector, la potencia de los derrubios es de 4 $\mathrm{m}$. La muestra M1, tomada a $4 \mathrm{~m}$ de profundidad, arrojó una edad de $10775 \pm 325$ años cal BP (Figura 3). En cambio, M2,

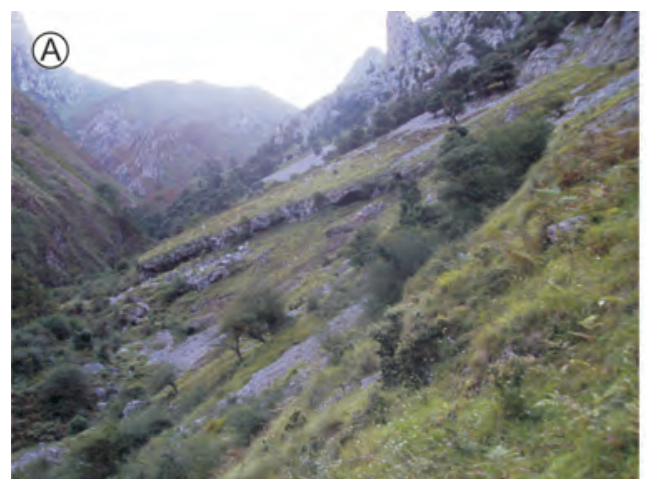

obtenida a $1,7 \mathrm{~m}$ de profundidad, tiene una antigüedad de $5175 \pm 135$ años cal BP (Figura 3). Por su parte, los resultados de las relaciones isotópicas en el carbonato de M1 muestran valores más ligeros de $\delta^{18} \mathrm{O}_{\mathrm{PDB}}$ $(-8,29 \%$, ) que en el caso de M2 (-5.18\%0; Tabla 1). A su vez, los resultados de $\delta^{13} \mathrm{C}_{\mathrm{PDB}}$ para M1 y M2 fueron respectivamente de -3.03 y de $-8.87 \%$.

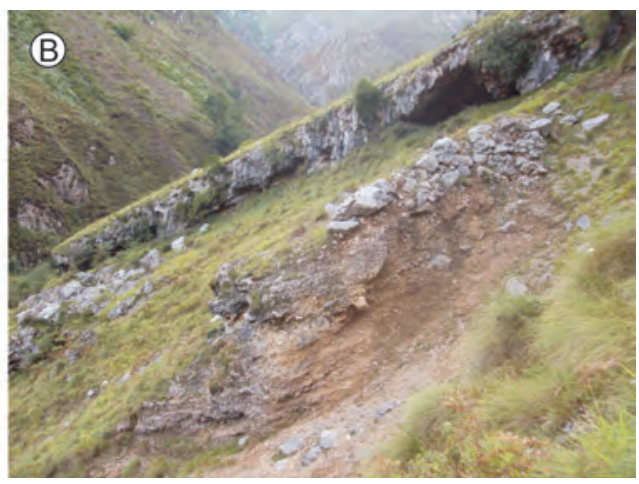

Fig. 4. Derrubios estratificados en la vertiente meridional de la Sierra de Dobros (A), y detalle de los mismos (B).

\begin{tabular}{|c|c|c|c|}
\hline Muestra & Fecha análisis & $\mathbf{\delta}^{\mathbf{1 3}} \mathbf{C}_{\mathbf{P D B} \%}$ & $\mathbf{\delta}^{18} \mathbf{O}_{\text {PDB \% }}$ \\
\hline M1 & 31 Mayo 2017 & -3.03 & -8.29 \\
\hline M2 & 31 Mayo 2017 & -8.87 & -5.18 \\
\hline
\end{tabular}

Tabla 1. Resultados de los análisis isotópicos efectuados en los derrubios estratificados de Praón (Picos de Europa).

\section{DISCUSIÓN}

\section{Los derrubios estratificados y cementados de Praón. Una dilatada morfogénesis a lo largo del Holoceno}

A la vista de los resultados descritos, interpretamos que, en las dos muestras datadas a 4 y $1,7 \mathrm{~m}$ de profundidad en los derrubios estratificados y cementados (M1 y M2), los restos de gasterópodos son aproximadamente sincrónicos a la formación de los derrubios y, sin duda, anteriores a la deposición del cemento calcáreo. Dicho proceso de cementación, entendemos que ha sido continuo a lo largo del tiempo de formación de los citados derrubios, tal y como evidencian los resultados de los análisis isotópicos realizados, en los que se han detectado diferentes condiciones de precipitación del cemento carbonatado para las dos muestras estudiadas. En la muestra M1, de $10775 \pm$ 325 años cal BP, predominaron unas condiciones más frías, tal y como evidencia la 
importante caída del isótopo $\delta^{18} \mathrm{O}_{\mathrm{PDB}}$, que alcanza valores de $-8,29 \%$, y está reflejado en las curvas de paleotemperaturas establecidas para el Holoceno (Figura 5). Estos valores son similares a los calculados por DOMÍNGUEZ-VILLAR et al. (2009) para el periodo frío (y húmedo) del Holoceno conocido como el evento 8.2, ampliamente documentado en sedimentos de lagos y espeleotemas (ej.: VON GRAFENSTEIN et al., 1998; ELLISON et al., 2006; HALD y KORSUM, 2008; DOMÍNGUEZ-VILLAR et al., 2008; Railsback et al., 2011). Los valores de $\delta^{18} \mathrm{O}_{\mathrm{PDB}}$ calculados para este evento se estiman en unos $-8 \%$, la mitad del valor asociado al enfriamiento ocurrido durante el Younger Dryas, y entre $\sim 0.7 \%$ y $1.0 \%$ de caída con respecto a la media del Holoceno (DOMÍNGUEZ-VILLAR et al., 2009). Las bajadas de la concentración de este isótopo han sido correlacionadas con bajadas significativas de la temperatura del Océano Atlántico y también con incrementos muy notables en las precipitaciones (MARSHALL et al., 2007). En este sentido, CUFFEY et al. (1994) ha relacionado las bajadas de temperatura con las caídas de $\delta^{18} \mathrm{O}$ estableciendo un patrón de $0.33 \% /{ }^{\circ} \mathrm{C}$. Por su parte, DOMÍNGUEZ-VILLAR et al. (2009) han relacionado la caída del isótopo $\delta^{18} \mathrm{O}$ analizado en estalagmitas del norte de la Península Ibérica como originado por incrementos en la precipitación. Estos mismos argumentos son refrendados en el estudio de RAILSBACK et al. (2011). Por otra parte, no debemos olvidar que los factores ambientales locales también dejan o pueden dejar su huella en la señal isotópica, lo que hace que los resultados isotópicos del oxígeno procedente de carbonatos de origen continental sean, con relativa frecuencia, difíciles de interpretar (MARTÍN-CHIVELET y MUÑOZ-GARCÍA, 2015). En cualquier caso, cabe señalar que la génesis de M1 se sitúa en el tránsito Tardiglaciar/Holoceno (entre 11,6 y $10 \mathrm{ka}$ ), que según CUFFEY et al. (1994), estuvo definido por caídas importantes de la temperatura de duración variable.

En cambio, la muestra M2, con una antigüedad de $5175 \pm 135$ años cal BP, arroja un valor de $\delta^{18} \mathrm{O}_{\mathrm{PDB}}$ significativamente distinto a M1, concretamente de $-5.18 \%$ o. Según el patrón Holoceno de DOMÍNGUEZ-VILLAR et al. (2009), dicho valor estaría de acuerdo con valores del isotopo $(-5,5$ a $-6 \%$ ) asociados a momentos mucho más cálidos $\left(6 \pm 2^{\circ} \mathrm{C}\right)$ posteriores al episodio frío que acabó hace unos 8000 años. Además, los datos del isótopo $\delta^{13} \mathrm{C}$ concuerdan con esta interpretación, ya que el enriquecimiento en ${ }^{12} \mathrm{C}$ (valor más ligero de $\delta^{13} \mathrm{C}$ ) indica una mayor actividad biológica en el momento de precipitación de M2 que en M1 (RUNDEL et al., 1989). Por tanto, la morfogénesis de las gravas estratificadas y cementadas de Praón abarca gran parte del Holoceno -es decir, fueron generadas durante el estadio isotópico marino 1 (MIS-1)-, con independencia de la existencia de variaciones en las condiciones climáticas, en cada caso (Figura 5).

Aunque en esta primera aproximación al estudio de los derrubios estratificados presentes en un sector de la baja montaña de los Picos de Europa el número de muestras analizadas es reducido, tanto los resultados de las dataciones efectuadas como los correspondientes a los análisis isotópicos muestran una total coherencia, especialmente desde el punto de vista morfoestratigráfico. De este modo, los resultados de este trabajo evidencian que, derrubios estratificados como los estudiados, no tienen por qué corresponderse necesariamente desde el 
punto de vista cronológico con la fase fría y seca (Tardiglaciar) a la que tradicionalmente han sido adscritos de forma relativa en las Montañas Cantábricas. En unos casos dicha adscripción puede ser acertada, pero en otros puede ser errónea. En el caso del Pirineo Central, GARCÍA-RUIZ et al. (2001) señalan que la formación de derrubios estratificados en el valle de Bentué de Rasal y en el cañón de Devotas, se desarrolló principalmente durante dos periodos fríos: el máximo de la Última Glaciación y el Tardiglaciar (específicamente durante el Oldest Dryas). En el caso de la Cordillera Cantábrica el máximo de la Última Glaciación ha sido establecido entre 45 y $36 \mathrm{ka}$ (MIS 3) (PELLITERO, 2013; SERRANO et al., 2013; RODRÍGUEZ-RODRÍGUEZ et al., 2015; RUIZ-FERNÁNDEZ et al., 2016).

Habitualmente, en la morfogénesis y desarrollo de este tipo de depósitos de vertiente tienen gran importancia la gelifracción, la ausencia de vegetación en las paredes rocosas que actúan como área fuente de derrubios, así como la abundancia de aguas de fusión nival que producen el lavado de la vertiente y el arrastre de partículas hacia las partes bajas de la misma (STEIJN et al., 1995; STEIJN, 2011). Pero, en su formación, pueden estar involucrados muchos otros procesos, algunos de los cuales pueden desarrollarse bajo condiciones climáticas muy diversas, no necesariamente de frío extremo ni exclusivas de ambientes periglaciares sensu stricto (ej.: avalanchas de rocas, debris flows, etc.; STEIJN et al., 1995; GARCÍA-RUIZ et al., 2001; STEIJN, 2011). A su vez, las propiedades litológicas adquieren suma importancia en el desarrollo y tipo de depósitos estratificados de vertiente que se generan, especialmente la granulometría, la estratificación o el grado de flexión de los materiales (STEIJN, 2011).

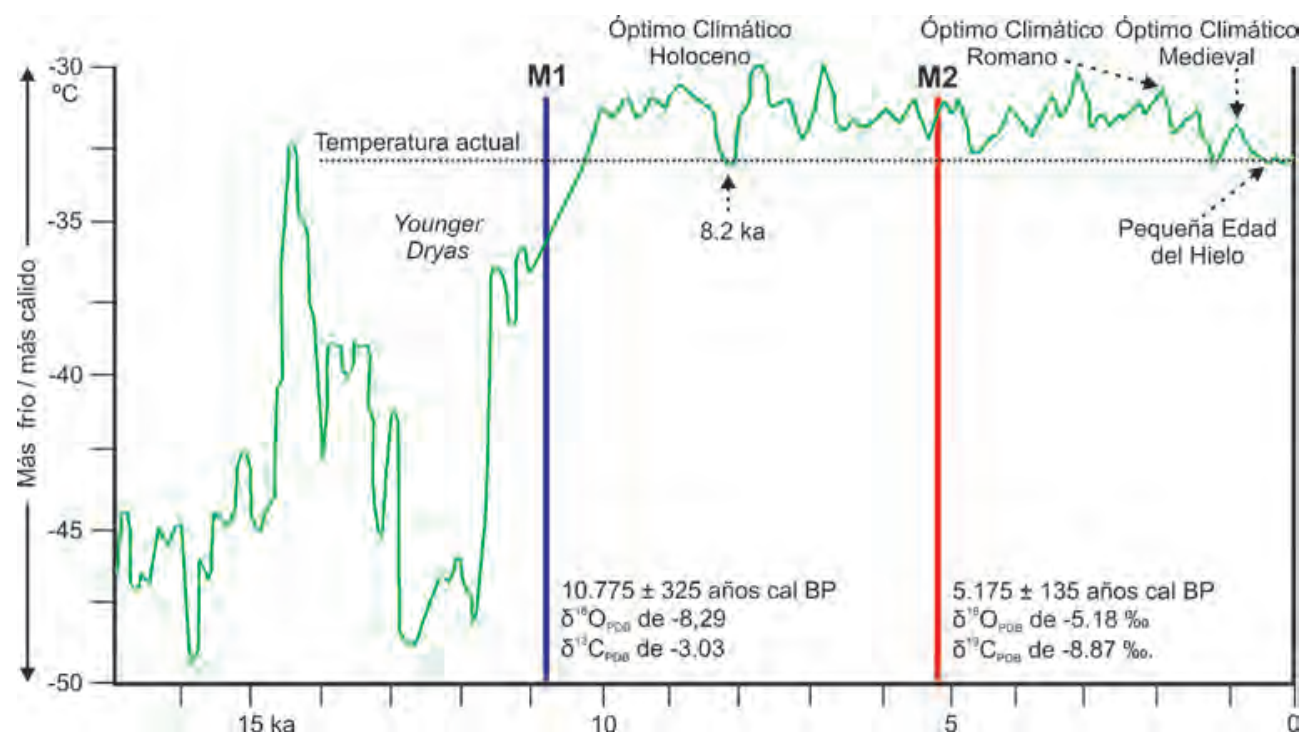

Fig. 5 Evolución de las temperaturas medias durante los últimos $15 \mathrm{ka}$ a partir de testigos de hielo del inlandsis groenlandés. Modificado de Williams et al. (2012). 
Por lo señalado, más que el control puramente climático, en la génesis de los derrubios estratificados estudiados en este trabajo han intervenido otros condicionantes no menos importantes, como los derivados de la estructura (características litológicas, disposición, diaclasado), la topografía, así como la disolución kárstica. En este sentido, la acción conjunta tanto de la disolución kárstica como de la crioclastia, puede dar lugar a la interacción entre ambos procesos, que se beneficiarían de forma recíproca (CASTAÑÓN Y FROCHOSO, 1998), pues, como señala NICOD (1972), la corrosión kárstica genera abundantes grietas y rugosidades propicias a la acción de los procesos de hielo-deshielo y, por su parte, las fisuras y oquedades ampliadas por la acción del hielo son ámbitos muy favorables para la concentración de la disolución kárstica. Esta interacción es lo que MAIRE (1990) definió como gelidisyunción, que puede llegar a constituir una importante fuente de derrubios.

\section{Las gonfolitas, brechas calcáreas cemen- tadas características de los Picos de Europa, generadas bajo condiciones diversas}

Los derrubios estratificados de Praón constituyen uno de los innumerables depósitos de vertiente cementados que recubren las laderas de los Picos de Europa, donde todos estos depósitos cementados, en conjunto, son conocidos bajo el término de gonfolitas (OBERMAIER, 1914). Estas brechas calcáreas, las cuales se encuentran cohesionadas por calcita gracias a la circulación de aguas saturadas de carbonatos por las laderas, llegan a ocupar superficies verdaderamente extensas. Esto ocurre, por ejemplo, entre los Invernales del Teju y los Puertos de Áliva
(Alto Duje); en la ladera meridional de la Sierra de Portudera entre Poncebos y Tielve; o en las vertientes de la periferia del Macizo del Cornión.

En concreto, en la cabecera del Valle del Duje, donde han sido estudiadas en deta1le, estas brechas constan de dos tramos: el inferior, de origen mixto (especialmente dinámica torrencial y movimientos en masa), está compuesto por fragmentos calcáreos heterométricos, sin clasificar y algo desgastados, entre los que se intercalan muy ocasionalmente lechos de gravas angulosas. Sobre esta base, se apoya un conjunto de gravas calcáreas angulosas, homométricas y ordenadas en lechos a las que se les ha atribuido un origen periglaciar, siendo el contacto entre ambas facies discordante (FROCHOSO Y CASTAÑÓN, 1986; CASTAÑÓN Y FROCHOSO, 1996). Por su parte, en el Macizo del Cornión no están presentes conjuntamente las dos facies. En la mayor parte de las ocasiones, los depósitos de gonfolita, situados en la parte inferior de las canales y, por tanto, a cotas altitudinales mucho más bajas que en el caso del Alto Duje, están integrados únicamente por derrubios heterométricos (cantos y bloques a veces de tamaños métricos), sin clasificar y de formas angulosas o subangulosas. Habitualmente, estas formaciones superficiales adquieren morfologías en cono (bien sea un único abanico o varios coalescentes), o en talud, siendo frecuente la presencia de bocas de conductos kársticos fósiles por encima de ellas (RUIZ-FERNÁNDEZ, 2013).

En la génesis de estos derrubios heterométricos han intervenido diversos procesos, como los torrenciales, ya que, tanto las aguas drenadas por las vertientes y los arroyos incipientes en episodios de precipitaciones intensas, como las aportadas por 
los mencionados conductos, se han encargado de redistribuir los materiales ladera abajo (FROCHOSO Y CASTAÑÓN, 1986; CASTAÑÓN Y FROCHOSO, 1996). No obstante, en la configuración de este tipo de depósitos también han desempeñado un papel esencial la caída de derrubios por acción de la gravedad, así como el desencadenamiento de desprendimientos rocosos (en ocasiones de grandes dimensiones), flujos de derrubios y otra serie de movimientos en masa rápidos. A su vez, la sucesiva circulación del agua saturada de carbonatos entre los fragmentos rocosos que componen los depósitos, se ha encargado de cementarlos (RUIZ-FERNÁNDEZ, 2013). Frecuentemente, estas gonfolitas alcanzan espesores de varias decenas de metros $y$, generalmente, tienen un escarpe muy abrupto en su frente (fruto de la erosión posterior), el cual suele estar karstificado, por lo que en sus paredes abundan las cuevas, con espeleotemas en su interior (Figura 6).

Se trata de depósitos claramente anteriores a la Último Ciclo Glaciar del Pleistoceno pues algunas de las lenguas de hielo que descendieron por la terminación S y SE del Macizo del Cornión los han erosionado (ej: área del Vallejón de las Horcadas y de la Vega de Arestas), incorporando bloques de gonfolita dentro del till, e incluso han depositado material morrénico directamente sobre ellos; como ocurre en Las Vegas, donde una morrena lateral del máximo avance dentro de la Última Glaciación, generada por la lengua que descendió por la canal de Capozo hasta alcanzar prácticamente el nivel de Cares, descansa directamente sobre un depósito de gonfolita o en la propia Vega de Arestas, en la que un arco morrénico frontal reposa igualmente sobre gonfolitas. Mediante la técnica del U-Th CASTAÑÓN Y FROCHOSO (1996) obtuvieron una edad de 192.7 +31.9/-23.3 ka para la base torrencial de las gonfolitas del Alto Duje, demostrando su carácter preglaciar con respecto a la Última Glaciación. A su presencia en los enclaves del Macizo del Cornión ya citados, debemos añadir la localización de estos depósitos en Angón, al Norte de Caín, en la parte baja de las canales de Trea y Culiembru, en Prehueles, al Suroeste de Poncebos y en las inmediaciones de Camarmeña, entre otros puntos del Macizo Occidental de los Picos de Europa (RUIZ-FERNÁNDEZ, 2013). 


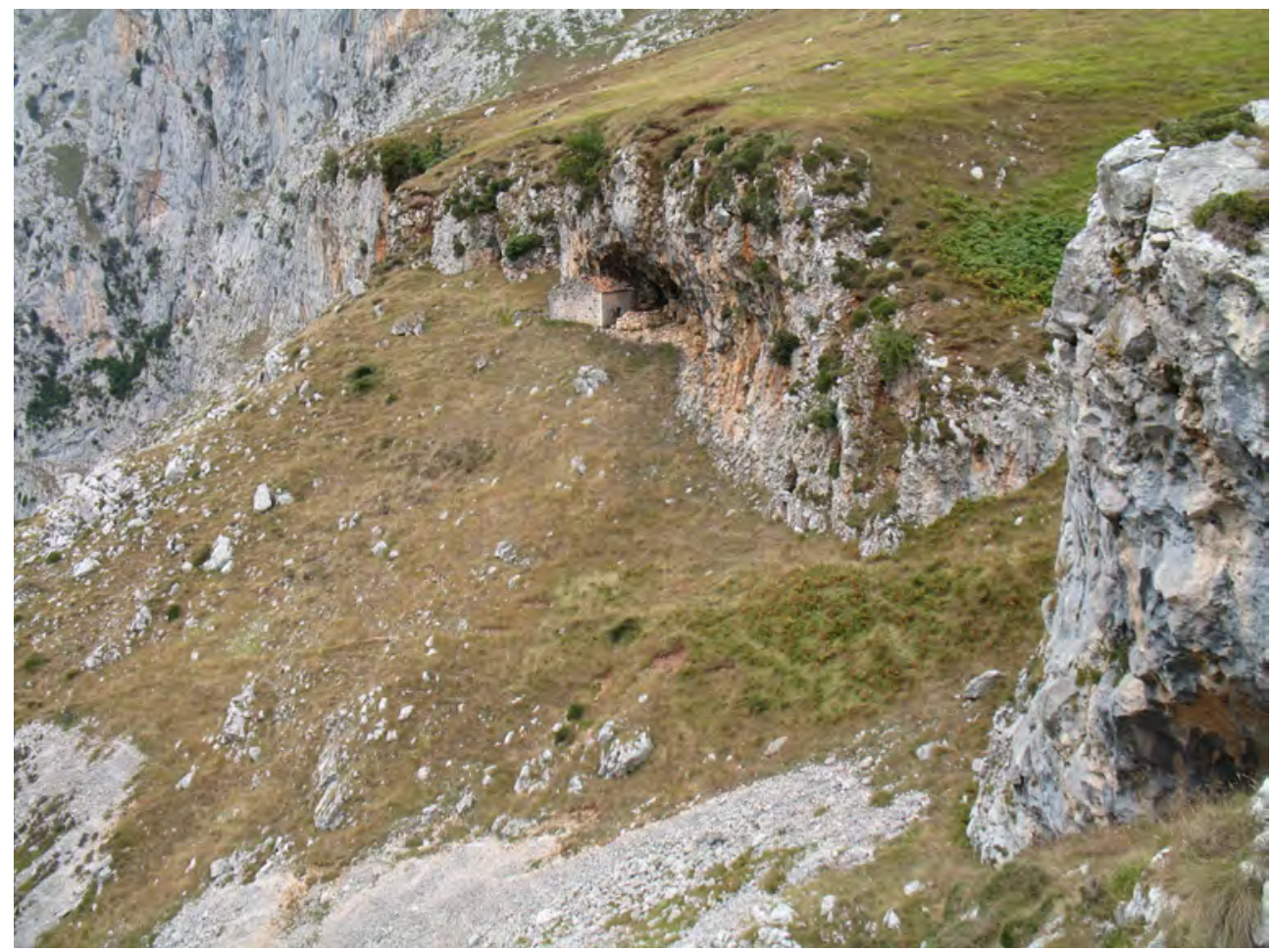

Fig. 6. Gonfolitas en Prehueles (encima de los Collaos, Ruta del Cares). Se observa en primer término la estructura del depósito, compuesto por bloques y cantos calcáreos de formas aristadas, sin ningún tipo de ordenación e intensamente cementados por calcita. Asimismo, en la imagen destaca nítidamente el abrupto escarpe característico de la porción distal de las gonfolitas, que, como se ha mencionado, suele contar con numerosas oquedades. Estas cuevas han sido aprovechadas históricamente como refugio del ganado, cerrándolas exteriormente con muros de piedra seca y llegando a levantar construcciones más complejas, como la cuadra que aparece en la fotografía.

En cambio, los depósitos cementados integrados por derrubios homométricos, angulosos y estratificados (la segunda facies de gonfolita), son menos frecuentes en el Macizo del Cornión. Estos últimos se sitúan a los pies de crestas y paredes rocosas, están incididos también en su frente y bordes laterales por la erosión reciente, y normalmente se hallan fosilizados en su parte proximal por canchales activos, denotando su carácter netamente heredado (Ruiz-Fernández, 2013). Sin embargo, su génesis es más reciente que en el caso de las gonfolitas formadas por clastos heterométricos sin ordenar, tal y como evidencia su posición estratigráfica a techo de las anteriores en el caso del Alto Duje (FROCHOSO Y CASTAÑÓN, 1986); su relación geométrica con la topografía actual, así como las dataciones de U-Th realizadas por CASTAÑÓN Y FROCHOSO (1996). Los citados autores han obtenido edades de 79.1 +7.3/-6.6 Ka y 55.4 +3.0/-3.0 $\mathrm{Ka}$ para las gravas que constituyen el tramo superior de las gonfolitas del Alto Duje. Se- 
gún los mismos autores estas gravas tienen un origen periglaciar.

Por tanto, las publicaciones de FROCHOSO Y CASTAÑÓN (1986) y CASTAÑ́N Y FROCHOSO, (1996), junto al presente trabajo, han estudiado dos tipos de depósitos estratificados y cementados del área de los Picos de Europa muy similares desde el punto de vista sedimentológico, y separados por una distancia relativamente escasa (de apenas $9 \mathrm{~km}$ en línea recta), los cuales, sin embargo, han sido generados en contextos muy diferentes. Mientras que a los situados en la cabecera del valle del Duje, a altitudes superiores a $900 \mathrm{~m}$, se les ha asignado un origen periglaciar y una antigüedad mucho mayor (FROCHOSO Y CASTAÑÓN, 1986; CASTAÑÓN Y FROCHOSO, 1996) (MIS-5 a MIS-3), los localizados en el área de Praón se desarrollan entre 205 y 410 $\mathrm{m}$ de altitud, y se han generado durante un dilatado periodo del Holoceno (MIS-1) con independencia de las condiciones climáticas; por lo que son otros factores los que explican la génesis de esta última generación de derrubios estratificados y cementados que, en este caso, no guarda relación directa con condiciones de tipo periglaciar. De hecho, según STEIJN (2011), relativamente pocos derrubios estratificados de vertiente parecen tener un origen totalmente periglaciar.

\section{CONCLUSIONES}

Se han realizado dos dataciones radiocarbónicas a 4 y 1,7 $\mathrm{m}$ de profundidad aprovechando la existencia de restos orgánicos (gasterópodos) insertos en un depósito conformado por derrubios homométricos, estratificados y cementados en el área de Praón, en la baja montaña del Macizo Occidental de los Picos de Europa. Los resul- tados cronológicos evidencian que, el proceso de formación de dichos derrubios, cuyo contexto geomorfológico y características sedimentológicas han sido establecidos previamente, se ha producido, al menos, entre el Holoceno inferior y el medio. Además, a partir de los análisis isotópicos efectuados, se han inferido las diferentes condiciones de precipitación del cemento carbonatado para las dos muestras estudiadas, las cuales en el caso de la muestra más antigua (10775 \pm 325 años cal BP) habrían sido más frías, tal y como evidencia la importante caída del isótopo $\delta^{18} \mathrm{O}_{\mathrm{PDB}}$, que alcanza valores de $-8,29$ $\%$, mientras la muestra más reciente $(5175 \pm$ 135 años cal BP) arroja un valor de $\delta^{18} \mathrm{O}_{\mathrm{PDB}}$ de $-5.18 \%$, por lo que la cementación se habría producido en condiciones mucho más cálidas. A esto debemos añadir que, los datos del isótopo $\delta^{13} \mathrm{C}$, indican una mayor actividad biológica en el momento de precipitación de esta segunda muestra.

La morfogénesis de estos depósitos de vertiente abarcaría gran parte del Holoceno, con independencia de la existencia de variaciones en las condiciones climáticas, no correspondiéndose por tanto, desde el punto cronológico, con la fase fría y seca (Tardiglaciar) a la que tradicionalmente han sido adscritos, de forma relativa, en las Montañas Cantábricas. Por el contrario, en su formación pueden estar involucrados distintos procesos, algunos de los cuales pueden desarrollarse bajo condiciones climáticas muy diversas, no necesariamente de frío extremo, ni exclusivas de ambientes periglaciares sensu stricto. De hecho, en el caso que nos ocupa, otros factores, como el estructural, el topográfico, así como la propia disolución kárstica, parecen haber sido más determinantes en la formación de los derrubios estudiados. 
Los resultados obtenidos en el presente estudio abren la puerta a una nueva línea de investigación en la montaña asturiana, la cual tendría por objeto la determinación de las condiciones climáticas y/o ambientales en las que sedimentaron depósitos estratificados de vertiente como los estudiados en esta primera contribución. Con la intención de robustecer las conclusiones obtenidas en este primer estudio, las aportaciones futuras incorporarán nuevos proxies, como los registros polínicos. Con esta misma intención, los análisis, que en este caso se han realizado sobre un número limitado de muestras con el único fin de realizar un planteamiento inicial de la problemática, se extenderán a otras localizaciones, involucrando un mayor número de muestras y de dataciones absolutas.

\section{AGRADECIMIENTOS}

Este trabajo se enmarca dentro de las actividades desarrolladas en el proyecto de investigación de excelencia con referencia CTM2016-77878-P, sufragado por el Ministerio de Economía, Industria y Competitividad del Gobierno de España. Los autores agradecen la ayuda del Dr. Antonio M. Álvarez-Valero en la interpretación de los resultados isotópicos.

\section{REFERENCIAS BIBLIOGRÁFICAS}

ALONSO, V. (1989) Glaciares rocosos fósiles en el área de Degaña-Leitariegos (Occidente de Asturias, Cordillera Cantábrica). Cuaternario y Geomorfología, 3 (1-4), 9-15.

BROSCHE, K.U. (1978) Formas actuales y límites inferiores periglaciares en la Península Ibérica. Estudios Geográficos, 151, 131-161.
CARRASCO, R.M., PEDRAZA, J., DOMÍNGUEZ-VILLAR, D., VILLA, J., WILLENBRING, J.K. (2013) The plateau glacier in the Sierra de Béjar (Iberian Central System) during its maximum extent. Reconstruction and chronology. Geomorphology 196, 83-93.

CASTAÑÓN, J.C., FROCHOSO, M. (1994) El periglaciarismo de la Cordillera Cantábrica. En: Periglaciarismo en la Península Ibérica, Canarias y Baleares. Monografías de la Sociedad Española de Geomorfología, $n^{\circ}$ 7, Gómez-Ortiz, A., Simón, M., Salvador, F., Eds., Servicio de Publicaciones de la Universidad de Granada, Granada, 75-91.

CASTAÑÓN, J.C., FROCHOSO, M. (1996) Hugo Obermaier y el glaciarismo pleistoceno. En: El hombre fósil 80 años después. Homenaje a H. Obermaier, Moure, A., Ed., Universidad de Cantabria, Santander, 153-175.

CASTAÑÓN, J.C., FROCHOSO, M. (1998)

La alta Montaña Cantábrica: condiciones térmicas y morfodinámicas en los Picos de Europa. En: Procesos biofísicos actuales en medios fríos, Gómez-Ortiz, A., Salvador, F., Schulte, L., García, A., Eds., Universidad de Barcelona, Barcelona, 113-132.

CUFFEY, K.M., ALLEY, R.B., GROOTES, P.M., BOLZAN, J.M., ANADAKRISHNAN, S. (1994) Calibration of the $\mathrm{d} 18 \mathrm{O}$ isotopic paleothermometer for central Greenland, using borehole temperatures. Journal of Glaciology, 40, 341-349.

DELMAS, M., GUNNELL, Y., BRAUCHER, R., CALVET, M. (2008) Exposure age chronology of the last glaciation in the eastern Pyrenees. Quaternary Research 69 (2), 231-241. 
DOMÍNGUEZ-VILLAR, D., CARRASCO, R.M., PEDRAZA, J., CHENG, H., EDWARDS, R.L., WILLENBRING, J.K. (2013) Early maximum extent of paleoglaciers from Mediterranean mountains during the last glaciation. Scientific Reports, 3, 20-34.

DOMÍNGUEZ-VILLAR, D. FAIRCHILD, I.J., BAKER, A., WANG, X., EDWARDS, R.L., CHENG, H. (2009) Oxygen isotope precipitation anomaly in the North Atlantic region during the 8.2 ka event. Geology, 37 (12), 1095-1098.

DOMÍNGUEZ-VILLAR, D., WANG, X.F., CHENG, H., MARTÍN-CHIVELET, J., EDWARDS, R.L. (2008) A high-resolution late Holocene speleothem record from Kaite Cave, northern Spain: $\otimes 180$ variability and possible causes. Quaternary International, 187, 40-51.

EHLERS, J., ASTAKHOV, V., GIBBARD, P.L., MANGERUD, J., SVENDSEN, J.I. (2006) Late Pleistocene glaciations in Europe. En: Encyclopaedia of Quaternary Science, Elias, S.A., Ed., Elsevier, Amsterdam, 1085-1095.

ELLISON, C.R.W., CHAPMAN, M.R., HALL, I.R. (2006) Surface and deep ocean interactions during the cold event 8200 years ago. Science, 312, 1929-1932.

FROCHOSO, M., CASTAÑÓN, J.C. (1986)

La evolución morfológica del alto valle del Duje durante el Cuaternario (Picos de Europa, NW España). Ería, 11, 193-209.

FROCHOSO, M., GONZÁLEZ-PELLEJERO, R., ALLENDE, F. (2013) Pleistocene glacial morphology and timing of last glacial cycle in Cantabrian mountains (Northern Spain): new chronological data from the Asón area. Central European Journal of Geosciences, 5, 12-27.
GALLINAR, D., RUIZ-FERNÁNDEZ, J., POBLETE, M.A., FERNÁNDEZ, A., GARCÍA, C., BEATO, S., MARINO, J.L. (2014) Morfología y evolución glaciar en el sector asturiano del Macizo de las Ubiñas. En: Avances de la Geomorfología en España 2012-2014, Schnabel, S., Gómez, A., Eds., Sociedad Española de Geomorfología, Cáceres, 543-546.

GARCÍA DE CELIS, A. (1991) Los glaciares rocosos de la Sierra del Suspirón (León). Polígonos, Revista de Geografía, 1, 9-20.

GARCÍA DE CELIS, A. (1997) El relieve de la Montaña Occidental de León. Secretariado de Publicaciones de la Universidad de Valladolid, Valladolid, 290 p.

GARCÍA DE CELIS, A. (2002) Formas periglaciares relictas en la Sierra de Suspirón (Cordillera Cantábrica, León): campos de bloques. En: Periglaciarsimo en Montaña y altas latitudes, Serrano E, García de Celis, A., Eds., Universidad de Valladolid, Valladolid, 37-52.

GARCÍA-RUIZ, J.M., MORENO, A., GONZÁLEZ-SAMPÉRIZ, P., VALERO-GARCÉS, B., MARTÍ-BONO, C. (2010) La cronología del último ciclo glaciar en las montañas del Sur de Europa. Una Revisión. Cuaternario y Geomorfología, 24 (1-2), 35-46.

GARCÍA-RUIZ, J.M., PALACIOS, D., DE ANDRÉS, N., VALERO-GARCÉS, B.L., LÓPEZ-MORENO, J.I., SANJUÁN, Y. (2014) Holocene and 'Little ice age' glacial activity in the Marboré Cirque, Monte Perdido Massif, Central Spanish Pyrenees. The Holocene, 24 (11), 1439-1452.

GARCÍA-RUIZ, J.M., VALERO-GARCÉS, B., GONZÁLEZ-SAMPÉRIZ, P., LORENTE, A., MARTÍ-BONO, C., 
BEGUERÍA, S., EDWARDS, L. (2001) Stratified scree in the Central Spanish Pyrenees: palaeoenvironmental implications. Permafrost and Periglacial Processes, 12 (3), 233-242.

GARCÍA-RUIZ, J.M., VALEROGARCÉS, B., MARTÍ-BONO, C., GONZÁLEZ-SAMPÉRIZ，P. (2003) Asynchroneity of maximum glacier advances in the central Spanish Pyrenees. Journal of Quaternary Science, 18 (1), 61-72.

GÓMEZ-ORTIZ, A., PALACIOS, D., PALADE, B., VÁZQUEZ-SELEM, L., SALVADOR-FRANCH, F. (2012) The deglaciation of the Sierra Nevada (Southern Spain). Geomorphology, 159160, 93-105.

GÓMEZ-VILLAR, A., GONZÁLEZGUTIÉRREZ, R.B., REDONDO-VEGA, J.M., SANTOS-GONZÁLEZ, J. (2011) Distribución de glaciares rocosos relictos en la Cordillera Cantábrica. Cuadernos de Investigación Geográfica, 37 (2), 49-80.

GONZÁLEZ-GUTIÉRREZ，R.B. (2002) El relieve de los valles del Torío y Curueño (Montaña Cantábrica Leonesa). Secretariado de Publicaciones de la Universidad de León, León, 267 p.

GONZÁLEZ-TRUEBA，J.J. (2007) Geomorfología del Macizo Central del Parque Nacional Picos de Europa, con Mapa geomorfológico E. 1:25.000. OAPN, Ministerio de Medio Ambiente, Madrid, $231 \mathrm{p}$.

GONZÁLEZ-TRUEBA, J.J., SERRANO, E. (2010) La nieve en los Picos de Europa. Cuadernos de Investigación Geográfica, 36 (2), 61-84.

GUTIÉRREZ-CLAVEROL, M., LUQUECABAL, C. (2000) La minería en los Picos de Europa. Noega, Oviedo, 303 p.
HALD, M., KORSUM, S. (2008) The 8200 cal. yr BP event reflected in the Artic fjord, Van Mijenfjorden, Svalbard. The Holocene, 18, 981-990.

JIMÉNEZ, M., FARIAS, P. (2002). New radiometric and geomorphologic evidences of a last glacial maximum older than $18 \mathrm{ka}$ in SW European mountains: the example of Redes Natural Park (Cantabrian Mountains, NW Spain). Geodinamica Acta 15, 93-101.

JIMÉNEZ, M., RODRÍGUEZ-RODRÍGUEZ, L., GARCÍA-RUIZ, J.M., DOMÍNGUEZ-CUESTA, M.J., FARIAS, P., VALERO-GARCÉS, B., MORENO, A., RICO, M., VALCÁRCEL, M. (2013) A review of glacial geomorphology and chronology in northern Spain: timing and regional variability during the last glacial cycle. Geomorphology 196, 50-64.

JOLY, F. (1997) Glossaire de géomorphologie. Base de données sémiologiques pour la cartographie. Armand Colin, París, $325 \mathrm{p}$.

JULIVERT, M., NAVARRO, D. (1984) Mapa Geológico de España. Escala 1:50.000. Hoja de Beleño (n $\left.{ }^{\circ} 55,15-05\right)$. Instituto Geológico y Minero de España, Madrid, 47 p. y mapa desplegable.

MAIRE, R. (1990) La haute montagne calcaire. Karsts, cavités, remplissages, Quaternaire, paléoclimats. KarstologiaMémories, 3, Association Française de karstologie y Fédération Française de Spéléologie, La Ravoire, 731 p.

MARCO MOLINA, J.A. (2000) Derrubios estratificados en la Sierra de Aitana, Alicante (España). Ería, 51, 79-92.

MARCO MOLINA, J.A., GIMÉNEZ FONT. P., PADILLA BLANCO, A. (2018) Procesos de clima frío en el ex- 
tremo NE peninsular de la Cordillera Bética. Revisión y síntesis de investigaciones previas. Cuaternario y Geomorfología, 32 (3-4), 39-56.

MARCOS, A. (1967) Estudio geológico del reborde NO de Los Picos de Europa (Región de Onís - Cabrales, Cordillera Cantábrica). Trabajos de Geología 1, 3946.

MARSHALL, J.D., LANG, B., CROWLEY, S.F., WEEDON, G.P., VAN CALSTEREN, P., FISHER, E.H., HOLME, R., HOLMES, J.A., JONES, R.T., BEDFORD, A., BROOKS, S.J., BLOEMENDAL, J., KIRIAKOULAKIS, K., BALL, J.D. (2007) Terrestrial impact of abrupt changes in the North Atlantic thermohaline circulation: Early Holocene, UK. Geology, 35, 639-642.

MARTÍN-CHIVELET, J., MUÑOZGARCÍA, M.B. (2015) Estratigrafía de isótopos de oxígeno y la reconstrucción de los cambios climáticos del pasado. Enseñanza de las Ciencias de la Tierra, 23 (2), 160-170.

MARTÍNEZ-GARCÍA, E. (1981) El Paleozoico de la Zona Cantábrica Oriental (Noroeste de España). Trabajos de Geología, 11, 95-127.

MARTÍNEZ-GARCÍA, E., RODRÍGUEZ-FERNÁNDEZ, L.R. (1984) Mapa Geológico de España. Escala 1:50.000. Hoja de Carreña - Cabrales ( ${ }^{\circ}$ 56, 16-05). Instituto Geológico y Minero de España, Madrid, 45 p. y mapa desplegable.

MERINO-TOMÉ, O. (2004) Estratigrafía, sedimentología y evolución tectonosedimentaria de las sucesiones estefanienses de la Región de Picos de Europa (Zona Cantábrica). Tesis Doctoral (inédita), Departamento de Geología de la Uni- versidad de Salamanca, Salamanca, 295 p.

MORENO, A., LÓPEZ-MERINO, L., LEIRA, M., MARCO-BARBA, J., GONZÁLEZ-SAMPÉRIZ, P., VALERO-GARCÉS, B. L., LÓPEZ-SÁEZ, J. A., SANTOS, L., MATA, P., ITO, E. (2011) Revealing the last 13,500 years of environmental history from the multiproxy record of a mountain lake (Lago Enol, northern Iberian Peninsula). Journal of Paleolimnology, 46, 327-349.

MUÑOZ-JIMÉNEZ，J. (1982) Geografía Física. El relieve, el clima y las aguas. En: Geografía de Asturias. Tomo I, Quirós, F., Dir., Ayalga Ediciones, Salinas, 1-271.

NAVARRO, D., LEYVA, F., VILLA, E. (1986) Cambios laterales de facies en el Carbonífero del Oriente de Asturias (Cordillera Cantábrica, Norte de España), Trabajos de Geología 16, 87-102.

NICOD, J. (1972) Pays et paysages du calcaire. Presses Universitaires de France, París, 244 p.

OBERMAIER, H. (1914) Estudio de los glaciares de los Picos de Europa, Museo Nacional de Ciencias Naturales, Madrid, 41 p.

OLIVA, M., SERRANO, E., GOMEZORTIZ, A., GONZÁLEZ-AMUCHASTEGUI, M.J., NIEUWENDAM, A., PALACIOS, D., PÉREZ-ALBERTI, A., PELLITERO-ONDICOL, R., RUIZFERNÁNDEZ, J., VALCÁRCEL M., VIEIRA, G., ANTONIADES, D. (2016) Spatial and temporal variability of periglaciation of the Iberian Peninsula. Quaternary Science Reviews, 137, 176-199.

OZOUF, J.C., COUTARD, J.P., LAUTRIDOU J.P. (1995) Grèzes, grèzes litées: Historique des définitions. Permafrost and Periglacial Processes, 6 (2), 85-87. 
PALACIOS, D., ANDRÉS, N., MARCOS, J., VÁZQUEZ-SELEM, L. (2012) Maximum glacial advance and deglaciation of the Pinar Valley (Sierra de Gredos, Central Spain) and its significance in the Mediterranean context. Geomorphology 177-178, 51-61.

PALACIOS, D., GÓMEZ-ORTIZ, A., DE ANDRÉS, N., VÁZQUEZ-SELEM, L., SALVADOR-FRANCH, F., OLIVA, M. (2015) Maximum extent of late Pleistocene glaciers and last deglaciation of La Cerdanya mountains, Southeastern Pyrenees. Geomorphology 231, 116-129.

PALACIOS, D., MARCOS, J., VÁZQUEZSELEM, L. (2011) Last Glacial Maximum and deglaciation of Sierra de Gredos, central Iberian Peninsula. Quaternary International, 233, 16-26.

PELLITERO, R. (2012) Geomorfología, paleoambiente cuaternario y geodiversidad en el Macizo de Fuentes CarrionasMontaña Palentina. Tesis Doctoral (inédita), Universidad de Valladolid, Valladolid, $1085 \mathrm{p}$.

PELLITERO, R. (2013) Evolución finicuaternaria del glaciarismo en el macizo de Fuentes Carrionas (Cordillera Cantábrica), propuesta cronológica y paleoambiental. Cuaternario y Geomorfología, 27 (1-2), 71-90.

PELLITERO, R., SERRANO, E., GONZÁLEZ-TRUEBA， J.J. (2011) Glaciares rocosos del sector central de la Montaña Cantábrica: indicadores paleoambientales. Cuadernos de Investigación Geográfica, 37 (2), 119-144.

PISABARRO, A., PELLITERO, R., SERRANO, E., GÓMEZ-LENDE, M., GONZÁLEZ-TRUEBA， J.J. (2017) Ground temperatures, landforms and processes in an Atlantic mountain. Can- tabrian Mountains (Northern Spain). Catena, 149, 623-636.

RAILSBACK L.B., LIANG, F., VIDAL ROMANÍ, J.R., GRANDALD'ANGLADE, A., VAQUEIRO RODRÍGUEZ, M., SANTOS FIDALGO, L., FERNÁNDEZ MOSQUERA, D., CHENG, H., EDWARDS, R.L. (2011) Petrographic and isotopic evidence for Holocene long-term climate change and shorter-term environmental shifts from a stalagmite from the Serra do Courel of northwestern Spain, and implications for climatic history across Europe and the Mediterranean. Palaeogeography, Palaeoclimatology, Palaeoecology 305, 172.184.

REDONDO-VEGA, J.M., GÓMEZ-VILLAR, A., GONZÁLEZ-GUTIÉRREZ, R.B. (2004) Localización y caracterización morfométrica de los glaciares rocosos relictos de la Sierra de Gistredo (Montaña Cantábrica, León). Cuadernos de Investigación Geográfica, 30, 3560.

RODRÍGUEZ-PÉREZ，C. (1995) Estudio geomorfológico del Puerto de San Isidro. Ería, 36, 63-87.

RODRÍGUEZ-PÉREZ, C. (1998) Las formas de relieve y la evolución geomorfológica de la sierra de Sobia (área central de Asturias). Ería, 46, 131-147.

RODRÍGUEZ-PÉREZ, C. (2015) El relieve de la Montaña Central Asturiana: la Sierra de Sobia y el Macizo de Somiedo. Real Instituto de Estudios Asturianos, Oviedo, 178 p.

RODRÍGUEZ-RODRÍGUEZ, L., JIMÉNEZ, M., DOMÍNGUEZ, M.J., ARANBURU, A. (2015) Research history on glacial geomorphology and geochronology of the Cantabrian Moun- 
tains, north Iberia $\left(43-42^{\circ} \mathrm{N} / 7-2^{\circ} \mathrm{W}\right)$. Quaternary International, 364, 6-21.

RODRÍGUEZ-RODRÍGUEZ, L., JIMÉNEZ-SÁNCHEZ, M., DOMÍNGUEZCUESTA, M.J., ARANBURU, A., (2014a) Research history on glacial geomorphology and geochronology of the Cantabrian Mountains, north Iberia $\left(43-42^{\circ} \mathrm{N} / 7-2^{\circ} \mathrm{W}\right)$. Quaternary International, 364, 6-21.

RODRÍGUEZ-RODRÍGUEZ, L., JIMÉNEZ-SÁNCHEZ, M., DOMÍNGUEZCUESTA, M.J., RICO, M.T., VALEROGARCÉS, B. (2011) Last deglaciation in northwestern Spain: new chronological and geomorphologic evidence from the Sanabria region. Geomorphology 135, 48-65.

RODRÍGUEZ-RODRÍGUEZ, L., JIMÉNEZ-SÁNCHEZ, M., DOMÍNGUEZCUESTA, M.J., RINTERKNECHT, V., PALLÁS, R., BOURLÉS, D., VALERO-GARCÉS, B. (2014b) A multiple dating-method approach applied to the Sanabria Lake moraine complex (NW Iberian Peninsula, SW Europe). Quaternary Science Reviews, 83, 1-10.

RUIZ-FERNÁNDEZ, J. (2006a) El paisaje natural de la Sierra de Juan Robre y Jana (Oriente de Asturias). Real Instituto de Estudios Asturianos, Oviedo, $191 \mathrm{p}$.

RUIZ-FERNÁNDEZ, J. (2006b) El paisaje vegetal de la Sierra de Juan Robre y Jana (Oriente de Asturias). Estudios Geográficos, LXVII, 260, 141-168.

RUIZ-FERNÁNDEZ, J. (2011) Geomorphological map of an Atlantic mid-height mountain area: the Juan Robre and Jana Ridge (Cantabrian Range, Northwest Spain). Journal of Maps, 7 (1), 260-272.

RUIZ-FERNÁNDEZ, J. (2013) Las formas de modelado glaciar, periglaciar $y$ fluviotorrencial del Macizo Occidental de los Picos de Europa (Cordillera Cantábrica). Tesis Doctoral (inédita), Departamento de Geografía de la Universidad de Oviedo, Oviedo, 314 p.

RUIZ-FERNÁNDEZ, J. (2015) Las formas de modelado glaciar, periglaciar y fluviotorrencial del Macizo Occidental de los Picos de Europa (Cordillera Cantábrica). Boletín de la Asociación de Geógrafos Españoles, 68, 581-587.

Ruiz-Fernández, J., González-Trueba, J.J., Poblete, M.A. (2008) La montaña media cabraliega". En: De Castilla al Mar. La naturaleza del paisaje en la Montaña Cantábrica, Ruiz Flaño, P., Serrano, E., Poblete, M.A., Ruiz-Fernández, J., Eds., Asociación de Geógrafos Españoles Universidad de Valladolid - Universidad de Oviedo, Valladolid, 99-124.

RUIZ-FERNÁNDEZ, J., OLIVA, M., CRUCES, A., LOPES, V., FREITAS, M.C., ANDRADE, C., GARCÍAHERNÁNDEZ, C., LÓPEZ-SÁEZ, J.A., GERALDES, M. (2016) Environmental evolution in the Picos de Europa (Cantabrian Mountains, SW Europe) since the Last Glaciation. Quaternary Science Reviews, 138, 87-104.

RUIZ-FERNÁNDEZ, J., OLIVA, M., HRBÁČEK, F., VIEIRA, G., GARCÍAHERNÁNDEZ, C. (2017) Soil temperatures in an Atlantic high mountain environment: The Forcadona buried ice patch (Picos de Europa, NW Spain). Catena, 149, 637-647.

RUIZ-FERNÁNDEZ， J., POBLETE, M.A., GARCÍA, C. (2014) Características morfoclimáticas y procesos y formas periglaciares actuales en el Macizo Occidental de los Picos de Europa (Cordillera Cantábrica). En: Avances, métodos y 
técnicas en el estudio del periglaciarismo, Gómez-Ortiz A., Salvador F., Oliva M., Salvà, M., Eds., Universidad de Barcelona, Barcelona, 91-103.

RUNDEL, P.W., EHLERINGER, J.R., NAGY K.A. (1989) Stable Isotopes in Ecological Research. Springer Verlag, New York, 525 p.

SANJURJO, J., FERNÁNDEZ, D., VIDAL ROMANÍ, J.R. (2009) Assessing the age-weathering correspondence of cosmogenic $21 \mathrm{Ne}$ dated Pleistocene surfaces by the Schmidt Hammer. Earth Surface Processes and Landforms, 34, 1121-1125. SÁNCHEZ, L., TRUYOLS, J. (1983) El Carbonífero de la Región de Picos de Europa. En: Carbonífero y Pérmico de España. X Congreso Internacional de Estratigrafía y Geología del Carbonífero, Martínez Díaz, C., Ed., Instituto Tecnológico y Geominero de España, Madrid, 106-115.

SANTOS-GONZÁLEZ, J. (2010) Glaciarismo y periglaciarismo en el Alto Sil, Provincia de León (Cordillera Cantábrica). Tesis Doctoral (inédita), Departamento de Geografía y Geología de la Universidad de León, León, 689 p.

SANTOS-GONZÁLEZ, J., GONZÁLEZGUTIÉRREZ, R.B., GÓMEZ-VILLAR, A., REDONDO-VEGA, J.M. (2009) Ground thermal regime in the vicinity of relict rock glaciers (Cantabrian Mountains, NW Spain). Finisterra, 87, 35-44.

SERRANO, E., GONZÁLEZ-TRUEBA, J.J. (2004) Morfodinámica periglaciar en el grupo Peña Vieja (Macizo Central de los Picos de Europa -Cantabria-). Cuaternario y Geomorfología, 18 (3-4), 73-88.

SERRANO, E., GONZÁLEZ-TRUEBA, J.J., GONZÁLEZ-GARCÍA, M. (2012)
Mountain glaciation and paleoclimate reconstruction in the Picos de Europa (Iberian Peninsula, SW Europe). Quaternary Research, 78, 303-314.

SERRANO, E., GONZÁLEZ-TRUEBA, J.J., PELLITERO, R., GONZÁlLZGARCÍA, M., GÓMEZ, M. (2013) Quaternary glacial evolution in the Cantabrian mountains (Northern Spain). Geomorphology, 196, 65-82.

STEIJN, H.V. (2011) Stratified slope deposits: periglacial and other processes involved. Geological Society of London, Special Publications, 354, 213-226.

STEIJN, H.V., BERTRAN P., FRANCOU B., TEXIER J.P., HÉTU, B. (1995) Models for the genetic and environmental interpretation of stratified slope deposits: Review. Permafrost and Periglacial Processes, 6 (2), 125-146.

VIDAL ROMANÍ, J.R., FERNÁNDEZ MOSQUERA, D. (1999) Cronología glaciar pleistocena de la Serra de Gerês, (Norte de Portugal). Estudos Do Quaternário 2, 57-64.

VIDAL ROMANÍ, J.R., FERNÁNDEZ MOSQUERA, D., MARTÍ, K., DE BRUM FERREIRA, A. (1999) Nuevos datos para la cronología glaciar pleistocena en el NW de la Península Ibérica. Cadernos do Laboratorio Xeolóxico de Laxe 24, 7-29.

VON GRAFENSTEIN, U., ERLENKEUSER, H., MÜLLER, J., JOUZEL, J., JOHNSEN, S. (1998) The cold event 8200 years ago documented in oxygen isotope records of precipitation in Europe and Greenland. Climate Dynamics, 14, 73-81.

WAGNER, R.H. (1967) Apuntes sobre las floras de la zona de Gamonedo Cabrales en la parte oriental de Asturias. Trabajos de Geología 1, 47-58. 
WILLIAMS, R.S., FERRIGNO, J.G. (2012) State of the Earth's cryosphere at the beginning of the 21st century-Glaciers, global snow cover, floating ice, and permafrost and periglacial environments. U.S. Geological Survey Professional Paper 1386-A, 546 p. 